\title{
A Summary of Inflammatory Bowel Disease
}

\author{
Dr. Niketh Desouza
}

\begin{abstract}
Background: Inflammatory bowel disease is a chronic group of inflammatory disorders which can be localised to the colon or spread across the entire gastrointestinal tract. The two main types of IBD are Crohn's disease and Ulcerative colitis. IBD affects about 1.6 million Americans, most of who are diagnosed before the age of 35 years ${ }^{I}$. IBD can be debilitating as well as lead to life threatening complications. In 2013, IBD accounted for 51,000 deaths worldwide ${ }^{2}$. Death is not caused by IBD itself but by complications of IBD which include bowel perforation and toxic megacolon. There can be extra-intestinal manifestations such as iritis, uveitis, ankylosing spondylitis, primary sclerosing cholangitis, pyodermagangrenosum and erythema nodosum. Individuals with $I B D$ are also at an increased risk of developing colon cancer. Crohn's disease and Ulcerative colitis can be differentiated by the location of the disease and nature of inflammatory changes. Ulcerative colitis is restricted to the rectum and colon whereas Crohn's disease can affect any part of the gastrointestinal tract, from the mouth to the anus. In Crohn's disease there is transmural inflammation (full thickness) whilein Ulcerative colitis there is mucosal and submucosalinvolvement only. It is a lifelong condition in which individuals will experience flare-ups followed by a period of remission in which no symptoms may be experienced.
\end{abstract}

Keywords: Inflammatory bowel disease, Ulcerative colitis, Crohn's disease.

\section{Introduction}

Both Ulcerative colitis and Crohn's disease will present with symptoms of abdominal pain, diarrhea, bloody stools, weight loss and fever. Some of the risk factors for developing IBD are alterations in the intestinal bacteria, a diet rich in animal derived protein and genetically susceptible individuals. Bloody diarrhea is more common in Ulcerative colitis. Diagnosis is done via endoscopy or barium studies. Blood tests can be helpful when the diagnosis is unclear. Crohn's disease will be Anti-Saccharomyces cerevisiae(ASCA) positive and Anti-neutrophil cytoplasmic antibodies (ANCA) negative while Ulcerative colitis will be ANCA positive and ASCA negative. They are caused by an interaction of genetic and environmental factors leading to an immunologic response causing inflammation. Treatment of IBD is individualised to each patient. Management is with immunosuppression, anti-inflammatory drugs and biological therapy. Surgery can be performed if medical therapy fails in Ulcerative colitis. Some of the rarer forms of IBD are Microscopic colitis, Behçet's disease and Diversion colitis. However we will focus on the two major subtypes, i.e. Crohn's disease and Ulcerative colitis.

\section{Ulcerative Colitis}

Ulcerative colitis is anautoimmune disease which causes ulcers and inflammation in the colon either in segments or completely. It has a bimodal distribution of age-specific incidence rates with two peaks. The first is between 15 to 25 years and the second peak is in the $6^{\text {th }}$ decade of life. There are about 10-12 per 100,000 new cases of Ulcerative colitis every year in the North America ${ }^{3}$. It is presumed to have a genetic component in its etiology. Current tobacco use and appendectomy before the age of 20 are said to have a protective effect inpreventing the development of Ulcerative colitis (however cessation of tobacco has a greater risk of developing Ulcerative colitis ${ }^{4,5}$ ). The clinical presentation usually consists of the patient presenting with chronic bloody diarrhea, rectal bleeding, abdominal pain and tenesmus. Weight loss may also be present. Extrainstestinal manifestations include ophthalmic (episcleritis, iritis, uveitis), cutaneous (pyodermagangrenosum, erythema nodosum), musculoskeletal (ankylosing spondylitis), primary sclerosing cholangitis, clubbing, deep vein thrombosis and autoimmune haemolytic anaemia. Diagnostic workup should include routine blood and stool investigations to rule out other causes as well as to check if there are any other extra-intestinal features of the disease present. An acute flare will have an elevated ESR and anaemia can be present if there is significant blood loss. Even though a sigmodoscopy can support the diagnosis of ulcerative colitis, a colonoscopy remains the best test to diagnose it as well as to see the extent of the disease. Endoscopic findings include pseudopolyps, loss of haustra (lead pipe appearance) and superficial ulceration. Microscopic morphology will show crypt abscess, ulcers, bleeding and no granulomas. Treatment depends on the severity of the disease and its extent. Treatment is aimed at inducing remission with medications, followed by maintenance medications to prevent relapse. For initial therapy, salicylates and mesalamine should be used. Corticosteroids can be used in severe cases. Budesonide is a glucocorticoid which can be used in acute exacerbations and has limited side effects due to its extensive first-pass effect in the liver. Immunosuppressive agents (azathioprine 
and 6-mercaptopurine) are used in patients who have chronic active disease (recurrent symptoms) to wean patients off steroids. Surgery can be curative in Ulcerative colitis for those who are refractory to steroid therapy. Patients should be counselled that the use of NSAIDs can lead to exacerbations. Colonoscopy is started 8 years after the diagnosis and then done yearly in Ulcerative colitis as well as Crohn's disease.

\section{Crohn's Disease}

Crohn's disease is a type of inflammatory bowel disease that can affect any part of the gastrointestinal tract from the mouth to the anus. Crohn's disease affects 7.1 per 100,000 people in the United States ${ }^{6}$. There is a higher rate of incidence in females (slightly higher rate), AshkenaziJewsand smokers. It commonly affects people in their teens and twenties and people in their 5 th to $7^{\text {th }}$ decade of life ${ }^{7}$. It is 3 to 20 times more common in first degree relatives and has a $55 \%$ occurrence in twins (if one has the disease) ${ }^{8,9}$. It is cause by a combination of bacterial, immune and environmental factors in individuals who are genetically susceptible. More common manifestations of Crohn's disease are skip lesions, masses, upper GI tract involvement, transmural granulomas, perianal disease, hypocalcemia, obstruction, nephrolithiasis (calcium oxalate stones), cholesterol gallstones and B12 deficiency (if the terminal ileum is involved). The clinical picture will usually involve an individual complaining of abdominal pain, chronic diarrhea which may or may not be bloody, fever and weight loss. Diagnosis can sometimes be challenging due to the inability to visualise the small intestine. Capsule endoscopy can aid in this area. Upper endoscopy should be done to exclude involvement of the upper gastrointestinal tract. Gross morphology will show transmural inflammation with cobblestone mucosa, bowel wall thickening (string sign on barium swallow), linear ulcers, creeping fat, fissures and fistulas. Microscopic morphology will show non-caseating granulomas and lymphoid aggregation.Crohn's disease is not curable and remission can be difficult to achieve. Relapse can be prevented by dietary changes, lifestyle modifications, medication, reduction of stress and moderate exercise along with activity. The best initial therapy is 5aminosalicyclc acid derivatives (mesalamine). Hydrocortisone can be used in severe attacks. Once the disease is in remission immunomodulators (azathioprine and 6MP) can be used to prevent relapse and long term use of steroid. Infliximab is a TNF inhibitor which is used in Crohn's disease when there is fistula formation. PPD screening should be done prior to initiating Infliximab as it can reactivate latent tuberculosis. Those individuals who have perianal involvement should be started on ciprofloxacin and metronidazole. Crohn's disease cannot be cured by surgery and will reoccur at the site of surgery. However surgery is performed if there is stricture formation or obstruction.

\begin{tabular}{|c|c|c|c|}
\hline & & Crohn's Disease & Ulcerative Colitis \\
\hline 1) & Signs and symptoms & & \\
\hline- & Stool & May or may not be bloody & Usually bloody \\
\hline- & Tenusmus & More common & Less common \\
\hline- & Fever & Common & $\begin{array}{llll}\begin{array}{l}\text { Uncommon } \\
\text { disease) }\end{array} & \text { (except in } & \text { severe } \\
\end{array}$ \\
\hline- & Fistula & Common & Rare \\
\hline- & Weight loss & Common & Seldom \\
\hline 2) & Diagnostic findings & & \\
\hline- & Colon involvement & Usually & Always \\
\hline- & Perianal disease & Common & Seldom \\
\hline- & $\begin{array}{ll}\text { Masses } & \text { and } \\
\text { obstruction }\end{array}$ & Can be present & No obstruction \\
\hline- & $\begin{array}{ll}\begin{array}{l}\text { Fistulas } \\
\text { abscesses }\end{array} & \text { and } \\
\end{array}$ & Can be present & Absent \\
\hline- & $\begin{array}{ll}\text { Depth of } \\
\text { inflammation }\end{array}$ & Transmural & Mucosal and submucosal \\
\hline- & Rectal involvement & Rectal sparring & Usually present \\
\hline- & Granulomas & Non-caseating granulomas & No granulomas seen \\
\hline - & $\begin{array}{l}\text { Continuity of } \\
\text { inflammation }\end{array}$ & Non continuous (skip lesions) & Continuous \\
\hline 3) & Management & & \\
\hline & -Antibiotics & Effective & Not effective \\
\hline & -Surgery & Cannot cure & Can be curative \\
\hline
\end{tabular}

\section{Conclusion}

IBD can have an impact on the individual's quality of life due to diarrhea, vomiting, abdominal pain and other socially unwanted symptoms. It is an often lifelong disease and improving patient's understanding of the disease willimprove medication compliance and help in the management of symptoms. The main objective of treatment is to achieve remission and prevent relapses or flare-ups.Due to the chronic, unpredictable nature of 
the disease prolonged remission can be difficult to achieve.However there has been much progress in the management of IBD, and with the extensive research being presently conducted on IBD, this will only progress in the years to come.

\section{References}

[1]. CCFA: What Is Crohn's | What Is Colitis | What Is IBD.” Accessed May 21, 2016. http://www.ccfa.org/what-are-crohns-andcolitis/?referrer=https://www.google.co.in/.

[2]. GBD 2013 Mortality and Causes of Death, Collaborators (17 December 2014). "Global, regional, and national age-sex specific allcause and cause-specific mortality for 240 causes of death, 1990-2013: a systematic analysis for the Global Burden of Disease Study 2013.". Lancet 385: 117-71. doi:10.1016/S0140-6736(14)61682-2. PMC 4340604. PMID 25530442.

[3]. Büsch, K.; Ludvigsson, J. F.; Ekström-Smedby, K.; Ekbom, A.; Askling, J.; Neovius, M. (2014-01-01). "Nationwide prevalence of inflammatory bowel disease in Sweden: a population-based register study". Alimentary Pharmacology \& Therapeutics 39 (1): $57-$ 68. doi:10.1111/apt.12528. ISSN 1365-2036. PMID 24127738.

[4]. Andersson RE, Olaison G, Tysk C, Ekbom A (March 2001). "Appendectomy and protection against ulcerative colitis". The New England Journal of Medicine 344 (11): 808-14. doi:10.1056/NEJM200103153441104. PMID 11248156.

[5]. Boyko EJ, Koepsell TD, Perera DR, Inui TS (March 1987). "Risk of ulcerative colitis among former and current cigarette smokers". The New England Journal of Medicine 316 (12): 707-10. doi:10.1056/NEJM198703193161202. PMID 3821808.

[6]. Hiatt RA, Kaufman L; Kaufman (1988). "Epidemiology of inflammatory bowel disease in a defined northern California population". Western Journal of Medicine 149 (5): 541-6. PMC 1026530. PMID 3250100.

[7]. Baumgart DC, Sandborn WJ; Sandborn (2012). "Crohn's disease". The Lancet 380 (9853): 1590-605. doi:10.1016/S01406736(12)60026-9. PMID 22914295.

[8]. Satsangi J, Jewell DP, Bell JI; Jewell; Bell (1997). "The genetics of inflammatory bowel disease". Gut 40 (5): $572-4$. doi:10.1136/gut.40.5.572. PMC 1027155. PMID 9203931.

[9]. Tysk C, Lindberg E, Järnerot G, Flodérus-Myrhed B; Lindberg; Järnerot; Flodérus-Myrhed (1988). "Ulcerative colitis and Crohn's disease in an unselected population of monozygotic and dizygotic twins. A study of heritability and the influence of smoking". Gut 29 (7): 990-6. doi:10.1136/gut.29.7.990. PMC 1433769. PMID 3396969. 